\title{
Free Vibration and Buckling Analysis of Parabolic Frame Structures Oguzhan DAS ${ }^{1}$, Hasan OZTURK ${ }^{2}$, Can GONENLi ${ }^{1}$ \\ ${ }^{1}$ Dokuz Eylul University, The Graduate School of Natural and Applied Sciences, 35397 Buca, Izmir, Turkey \\ ${ }^{2}$ Dokuz Eylul University, Department of Mechanical Engineering 35397 Buca, Izmir, Turkey
}

\begin{abstract}
:
Numerous engineering structures take place in many fields such as construction, automotive, naval industry, aerospace, etc. Parabolic frame structures have a significant role in those industries. There are many gaps in terms of the literature studies about these structures. In this paper, free vibration and buckling behavior of parabolic frame structures by using the finite element method are investigated. The structure is modeled by considering a frame element that has three degrees of freedom and neglects the displacement in y-axis. In addition, two-bay parabolic frame structure with different radius of curvature is investigated. The numerical results are compared with the CAD model of the structure by using Solid Works for various cases. It is concluded that the results are in very good agreement with those results that are obtained from Solid Works. It is also understood that for the different radius of curvatures the approach that is used for finite element buckling analysis in perpendicular distributed loading case does not change.
\end{abstract}

Keywords: Finite Element Analysis, vibration, buckling, frame structure, parabolic frames

\section{Introduction}

Parabolic frame structures are used in various engineering fields such as construction, automotive, naval industry, aerospace, etc. However, the studies that take them into account are limited. Nevertheless, there are numerous studies about beams and curved beams that can contribute future works about parabolic frames. Leontovich [1] is the one who investigated the parabolic frames and arches. In this book, parabolic frames and arches are taken into account statically in various loading cases. Chidamparam and Leissa [2] studied on the vibration behavior of planar curved beams, arches, and rings. They review many studies that comprise in-plane vibrations, out of plane vibrations, coupled vibrations, nonlinear vibrations, etc. Kang et al. [3] worked on free vibration analysis of planar curved beams by utilizing wave propagation with general boundary conditions and supports. Zhu and Meguid [4] developed a new curved beam element that satisfies inextensible bending mode conditions by using a three-node locking free curved beam element. Akgöz and Civalek [5] investigated the free vibration analysis of axially functionally graded tapered Bernoulli-Euler microbeams. They utilized the Rayleigh-Ritz method in order to obtain the solution of the free transverse vibration problem. Pradhan and Chakravery [6] worked on the free vibration analysis of both Euler and Timoshenko functionally graded beams. They obtained the governing equations by using the Rayleigh-Ritz method. Eltaher et al. [7] studied on the vibration analysis of Euler-Bernoulli nanobeams. They employ the finite element method in order to obtain numerical results. Bazoune and Khulief [8] investigated the free vibration analysis of rotating tapered Timoshenko beams. They used a finite element beam that has four degrees of freedom including shear deformations. Cleghorn et al. [9] Studied on a finite element model for the vibration of rings with unsymmetrical cross-sections. They developed a finite element model for free, coupled in-plane and out of plane conditions. Fotouhi [10] performed the dynamic analysis of flexible beams with large deflections. Cantilever beam and rotating flexible robot arms are taken into account as example structures. Ozturk [11] studied on the vibration analysis of a pre-stressed laminated composite curved beam 
by employing the finite element method with a straight -beam element approach. The effects of orientation angle and vertical loading on the natural frequency are investigated for the first four modes. Kiral et al. [12] investigated the stability of delaminated composite beams via finite element analysis for different stacking sequences. Mehmood [13] studied the vibration analysis of frame structure that is subjected to moving loads. Basci et al. [14] presented an improved method for free vibration analysis of frame structures for various boundary conditions. Chan [15] performed a buckling analysis of structures that are composed of tapered members.

In this paper, the free vibration and buckling analysis of the single-bay and the two-bay isotropic parabolic frames are investigated. It is seen that there is not any study related to this topic in literature. The parabolic frame structures are modelled by considering Euler-Bernoulli beam theory. All equations are formulated and solved in MATLAB. In order to compare numerical results, the same structures are modelled and analyzed in SolidWorks.

\section{Theoretical Analysis}

\subsection{Finite Element Model}

The finite element method is employed in order to model the parabolic frame structure as seen in Fig.1. To satisfy all degrees of freedom for such structure, a two-nodded frame element with three degrees of freedom (DOF), which is shown in Fig.2, is taken into account.

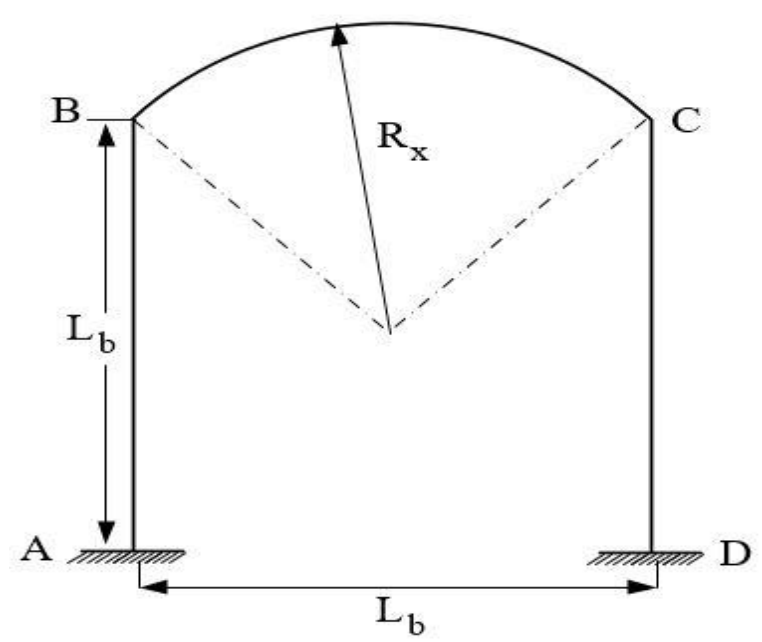

Figure 1: Parabolic frame structure

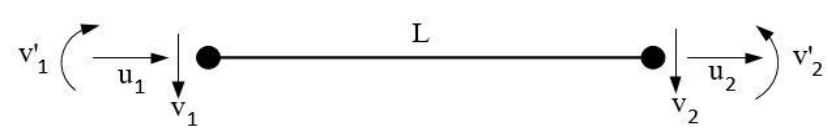

Figure 2: The frame element

The longitudinal displacement $\mathrm{u}$ is represented with a first-order polynomial equation while the bending displacement $\mathrm{v}$, is defined as a cubic function in order to satisfy the rotation effect.

$$
\begin{gathered}
u=a_{1}+a_{2} x \\
v=a_{3}+a_{4} x+a_{5} x^{2}+a_{6} x^{3}
\end{gathered}
$$

The slope $\mathrm{v}^{\prime}$, is equal to the first derivative of the bending displacement with respect to $\mathrm{x}$.

$$
\mathrm{v}^{\prime}=\frac{\mathrm{dv}}{\mathrm{dx}}
$$

The generalized displacement vector for the frame element can be expressed as 


$$
\boldsymbol{q}=\left[\begin{array}{llllll}
u_{1} & v_{1} & v^{\prime} & u_{2} & v_{2} & v^{\prime}{ }_{2}
\end{array}\right]
$$

The strain energy for frame element is given as

$$
\mathrm{U}_{\mathrm{e}}=\frac{1}{2} \mathrm{EI} \int_{0}^{\mathrm{L}} \frac{\partial^{2} \mathrm{v}}{\partial \mathrm{x}^{2}} \mathrm{dx}+\frac{1}{2} \mathrm{EA} \int_{0}^{\mathrm{L}} \frac{\partial^{2} \mathrm{u}}{\partial \mathrm{x}^{2}} \boldsymbol{d x}
$$

where $\mathrm{E}$ is the modulus of elasticity of the material, A is the cross-sectional area of the element and I is the second moment of inertia of the element. Eq.5 can be written in matrix form as

$$
U_{e}=\frac{1}{2} \boldsymbol{q}^{T} \boldsymbol{k}_{e} \boldsymbol{q}
$$

where $\mathbf{k}_{\mathbf{e}}$ is the element geometry matrix.

The Kinetic Energy for frame element is

$$
T_{e}=\frac{1}{2} \int_{0}^{L} \rho A\left(\dot{u}^{2}+\dot{v}^{2}\right) d x
$$

where $\rho$ is the density of the material. Writing Eq.7 in matrix form as

$$
T_{e}=\frac{1}{2} \boldsymbol{q}^{T} \boldsymbol{m}_{e} \boldsymbol{q}
$$

where $\mathbf{m}_{\mathbf{e}}$ is the element mass matrix. The work done by the applied load is expressed as

$$
V_{e}=\frac{1}{2} W \int_{0}^{L}\left(\frac{\partial v}{\partial x}\right)^{2} d x
$$

where

$$
P=W L_{b}
$$

where $\mathrm{P}$ represents the point load. Hence,

$$
V_{e}=\frac{1}{2} W \int_{0}^{L}\left(\frac{\partial v}{\partial x}\right)^{2} d x
$$

Writing Eq.11 in matrix form,

$$
V_{e}=\frac{1}{2} \boldsymbol{q}^{T} \boldsymbol{k}_{\boldsymbol{g} e} \boldsymbol{q}
$$

where $\mathbf{k}_{\mathbf{g e}}$ is the element geometry matrix.

Once all element matrices are obtained, they are needed to be transformed in terms of reference coordinates as it is given in Fig. 3 by using Eq.13 since the curvature and the structure itself is composed of straight beams.

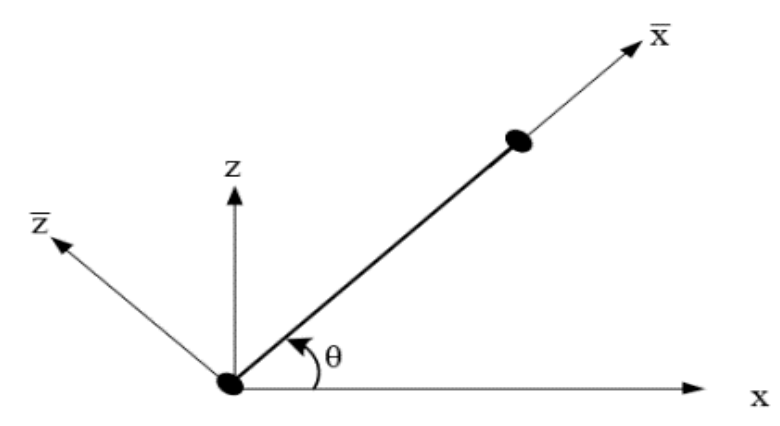

Figure 3: Transformation of local coordinates 


$$
\bar{k}_{e}=T^{T} k_{e} T, \bar{m}_{e}=T^{T} m_{e} T, \text { and } \bar{k}_{g e}=T^{T} k_{g e} T
$$

where $\mathbf{T}$ is the transformation matrix which is,

$$
\boldsymbol{T}=\left[\begin{array}{ccc}
\cos \theta & \sin \theta & 0 \\
-\sin \theta & \cos \theta & 0 \\
0 & 0 & 1
\end{array}\right]
$$

\subsection{Free Vibration Analysis}

The dynamic response of the parabolic frame structure can be obtained by using Lagrange's equation of motion as

and the eigenvalue problem is

$$
M \ddot{q}+K q=0
$$

$$
(\boldsymbol{K}-\lambda \boldsymbol{M}) \boldsymbol{q}=\mathbf{0}
$$

where $\mathbf{K}$ is the global stiffness matrix, $\mathbf{M}$ is the global mass matrix and $\lambda$ is the eigenvalue or, in other words, the natural frequency values of the system.

\subsection{Buckling Analysis}

The critical buckling load for a system is found by using the eigenvalue problem given in Eq. 17.

$$
\left(\boldsymbol{K}-P_{c r} \boldsymbol{K}_{\boldsymbol{g}}\right) \boldsymbol{q}=\mathbf{0}
$$

where $\mathbf{K}_{\mathbf{g}}$ is the global geometry matrix and $\mathrm{P}_{\mathrm{cr}}$ is the critical buckling load.

\section{Numerical Analysis}

In this study, free vibration and buckling analysis of parabolic frames are investigated. Four different radius of curvature values are selected in order to find out the effect of the curvature on the dynamic behavior and critical buckling load of the structure. To also investigate the thickness effect, two different thickness parameter is taken into account. Additionally, the two-bay structure is also considered for free vibration and buckling analysis. Material properties and geometric properties of the structure are given in Table 1. A MATLAB code is developed in order to solve the free vibration and buckling problem. The distributed

\begin{tabular}{|c|c|c|}
\hline Property & Symbol & Quantity \\
\hline Elastic Modulus & $\mathrm{E}$ & $69 \mathrm{GPa}$ \\
\hline Density & $\rho$ & $2700 \mathrm{~kg} / \mathrm{m}^{3}$ \\
\hline Poisson Ratio & $v$ & 0.33 \\
\hline \multicolumn{3}{|c|}{ Geometric Properties of the Structure } \\
\hline Beam Length & $\mathrm{L}_{\mathrm{b}}$ & $1000 \mathrm{~mm}$ \\
\hline \multirow{2}{*}{ Cross-section } & \multirow{2}{*}{$\frac{h}{h}$} & $\mathrm{~L}_{\mathrm{b}} / 100$ \\
\hline & & $\mathrm{L}_{\mathrm{b}} / 100$ \\
\hline
\end{tabular}
loading case given in Fig.4 is taken into account to solve the buckling problem. In order to simplify the problem, the distributed load is transformed into a two-point load that acts to the columns of the structure as seen in Fig.5.

Table 1: Material properties and geometry of the structure 


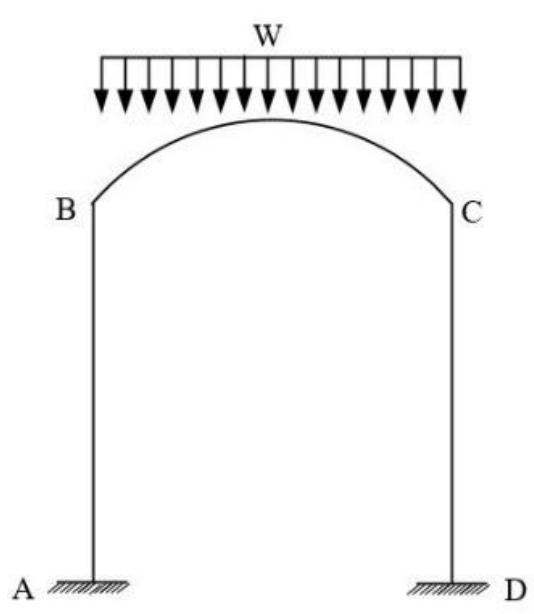

(a)

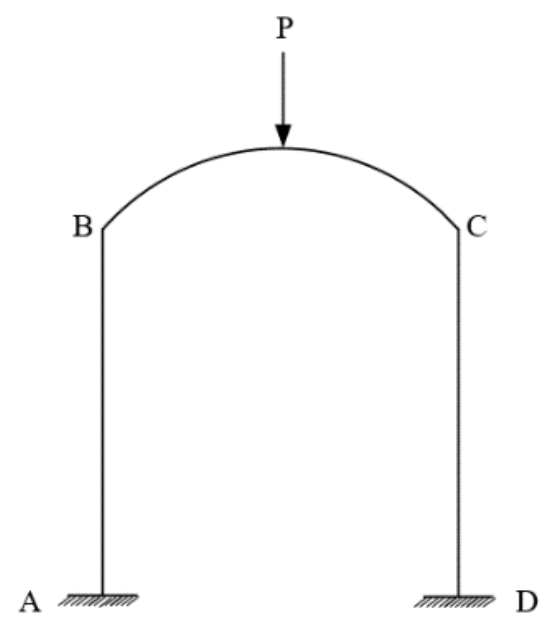

(b)

Figure 4: Distributed loading case (a) Equivalent loading (b)

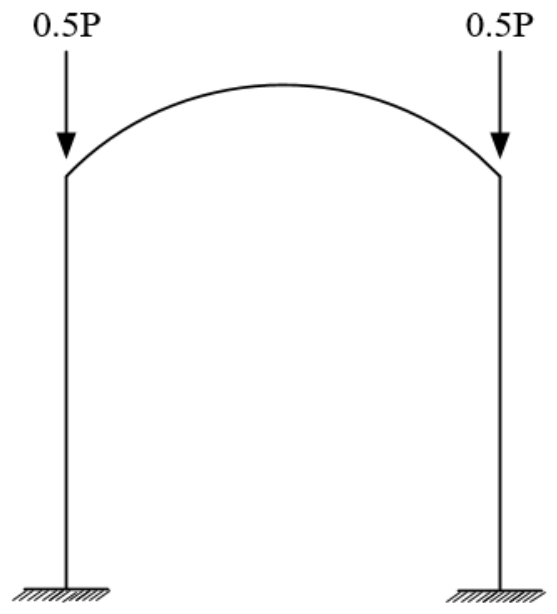

Figure 5: Equivalent loading case for parabolic frame structure

\subsection{Effect of the radius of curvature}

For a single bay structure, the effect of the radius of curvature $\left(\mathrm{R}_{\mathrm{xx}}\right)$ on dynamic behavior and critical buckling load are investigated. Different radius of curvatures is taken into account as is seen in Fig.6.

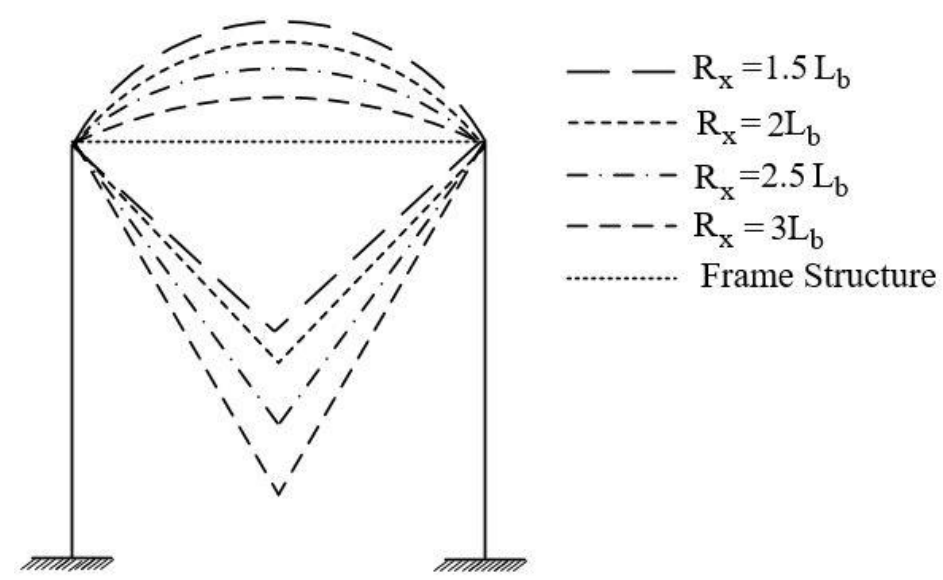

Figure 6: The parabolic frame structure with different curvatures 
Comparative results of free vibration analysis and critical buckling load of the parabolic frame structure for various curvature values are given in Tables 2 and 3.

Table 2: Free vibration and buckling analysis of the parabolic frame structure for $R_{x x}=1.5 L_{b}$ and $R_{x x}=2 L_{b}$ (N.F.: Natural Frequency Values, $\mathrm{P}_{\mathrm{cr}}$ : Critical Buckling Load, SW: SolidWorks Results, PS: Present Study Results, Err: Error)

\begin{tabular}{|c|c|c|c|c|c|c|}
\hline \multirow{2}{*}{$\begin{array}{c}N . F . \\
(H z)\end{array}$} & \multicolumn{3}{|c|}{$R_{x x}=1.5 L_{b}$} & \multicolumn{3}{c|}{$R_{x x}=2 L_{b}$} \\
\cline { 2 - 7 } & $\mathrm{SW}$ & $\mathrm{PS}$ & $\operatorname{Err}(\%)$ & $\mathrm{SW}$ & $\mathrm{PS}$ & $\operatorname{Err}(\%)$ \\
\hline $\mathrm{f}_{1}$ & 8.08 & 8.28 & $2.49 \%$ & 8.13 & 8.29 & $1.86 \%$ \\
\hline $\mathrm{f}_{2}$ & 30.49 & 31.87 & $4.49 \%$ & 31.09 & 32.05 & $3.08 \%$ \\
\hline $\mathrm{f}_{3}$ & 50.98 & 52.82 & $3.61 \%$ & 51.56 & 53.02 & $2.82 \%$ \\
\hline $\mathrm{f}_{4}$ & 61.34 & 60.22 & $1.84 \%$ & 60.54 & 59.61 & $1.53 \%$ \\
\hline $\mathrm{f}_{5}$ & 112.14 & 115.46 & $2.96 \%$ & 113.54 & 115.66 & $1.87 \%$ \\
\hline$P_{c r}(N)$ & 945.49 & 948.50 & $0.32 \%$ & 951.26 & 948.90 & $0.25 \%$ \\
\hline
\end{tabular}

Table 3: Free vibration and buckling analysis of the parabolic frame structure for $R_{x x}=2.5 L_{b}$ and $R_{x x}=3 L_{b}$ (N.F.: Natural Frequency Values, $\mathrm{P}_{\mathrm{cr}}$ : Critical Buckling Load, SW: SolidWorks Results, PS: Present Study Results, Err: Error)

\begin{tabular}{|c|c|c|c|c|c|c|}
\hline \multirow{2}{*}{$\begin{array}{c}N . F . \\
(H z)\end{array}$} & \multicolumn{3}{|c|}{$R_{x x}=2.5 L_{b}$} & \multicolumn{3}{c|}{$R_{x x}=3 L_{b}$} \\
\cline { 2 - 7 } & $\mathrm{SW}$ & $\mathrm{PS}$ & $\begin{array}{c}\text { Err } \\
(\%)\end{array}$ & $\mathrm{SW}$ & $\mathrm{PS}$ & Err (\%) \\
\hline $\mathrm{f}_{1}$ & 8.16 & 8.29 & $1.61 \%$ & 8.17 & 8.30 & $1.49 \%$ \\
\hline $\mathrm{f}_{2}$ & 31.43 & 32.16 & $2.30 \%$ & 31.64 & 32.23 & $1.87 \%$ \\
\hline $\mathrm{f}_{3}$ & 51.88 & 53.14 & $2.41 \%$ & 52.07 & 53.22 & $2.19 \%$ \\
\hline $\mathrm{f}_{4}$ & 60.05 & 59.26 & $1.33 \%$ & 59.68 & 59.03 & $1.09 \%$ \\
\hline $\mathrm{f}_{5}$ & 114.23 & 115.79 & $1.37 \%$ & 114.62 & 115.87 & $1.09 \%$ \\
\hline$P_{c r}(N)$ & 954.54 & 949.08 & $0.57 \%$ & 956.4 & 949.17 & $0.76 \%$ \\
\hline
\end{tabular}

The first five natural frequency values and the critical buckling load for four different curvatures are given in Tables 2 and 3. It is concluded that the present study is in very good agreement with SolidWorks results. As the curvature increases, the first three and the fifth natural frequency increase whereas the fourth natural frequency decreases. This is because all components of the structure have the same displacement characteristics in the fourth mode as seen in Fig. 7d. All mode shapes are the same for all curvatures and given in Fig.7. The critical buckling load increases as the radius of curvature increases.
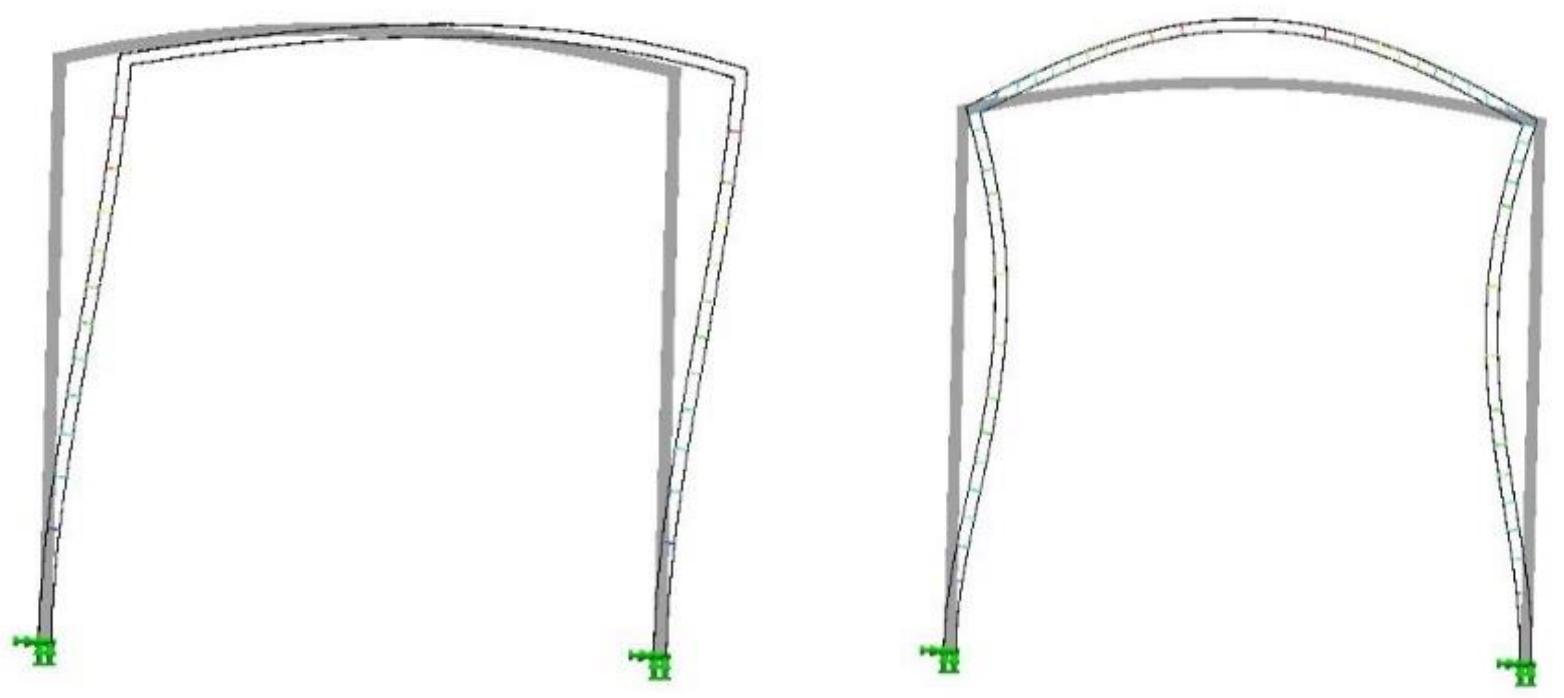
(a)

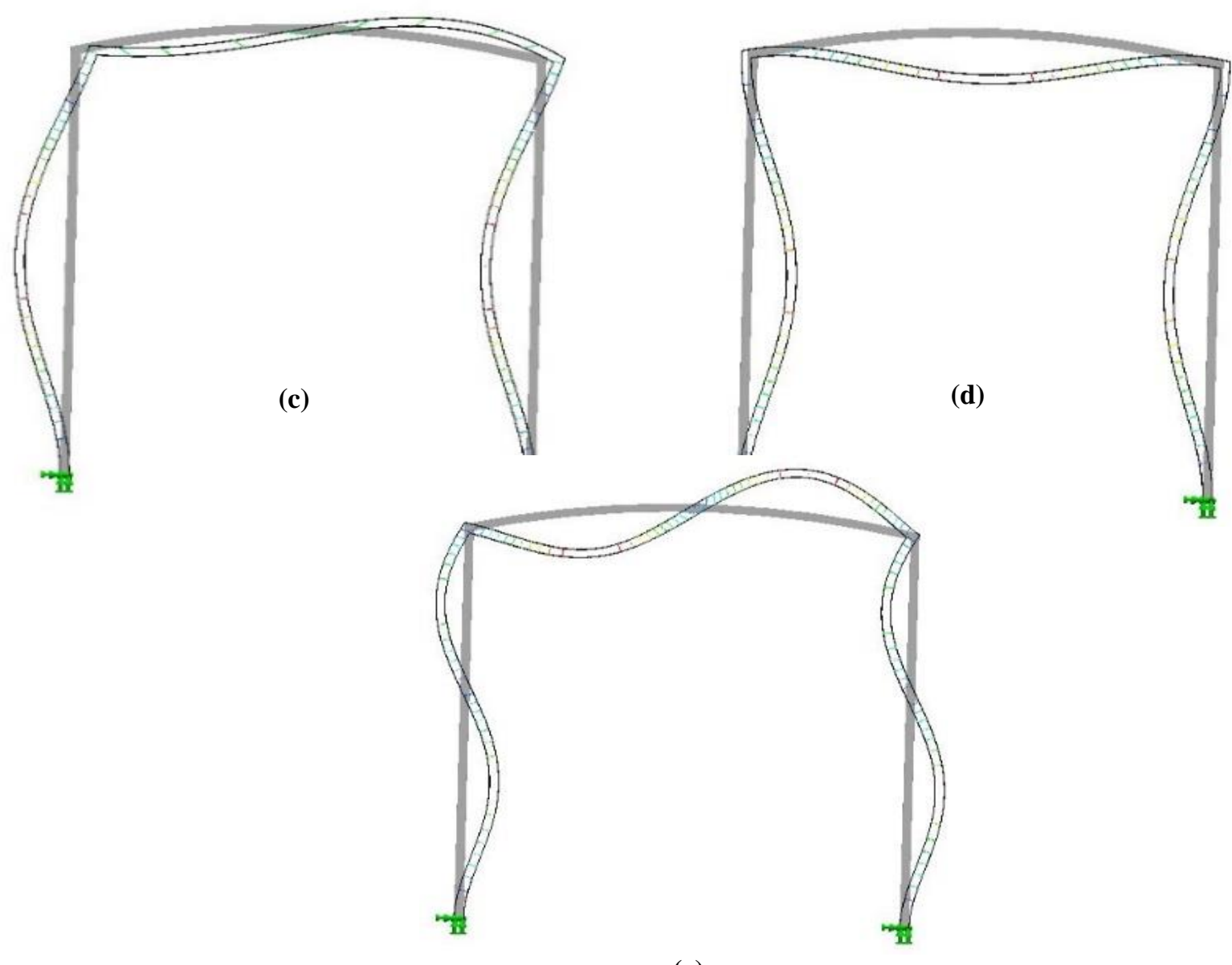

Figure 7: The first five modes of the parabolic frame structure

Comparative results of free vibration analysis and critical buckling load of the straight frame structure $\left(R_{x x}=\infty\right)$ for various curvature values are given in Table 4 . It is seen that the first three and fifth natural frequencies are at the highest values when compared with the results given in Tables 2 and 3. In contrast, the fourth natural frequency is at the lowest value as is expected. The critical buckling load is also at its highest value when compared with Tables 2 and 3.

Table 4: Free vibration and buckling analysis of the straight frame structure for $R_{x x}=\infty$ (N.F.: Natural Frequency Values, $\mathrm{P}_{\mathrm{cr}}$ : Critical Buckling Load, SW: SolidWorks Results, PS: Present Study Results, Err: Error)

\begin{tabular}{|c|c|c|c|}
\hline \multirow{2}{*}{$\begin{array}{c}\text { N.F. } \\
(H z)\end{array}$} & \multicolumn{3}{|c|}{ Straight Frame Structure $\left(R_{x x}=\infty\right)$} \\
\cline { 2 - 4 } & $\mathrm{SW}$ & $\mathrm{PS}$ & Err $(\%)$ \\
\hline $\mathrm{f}_{1}$ & 8.24 & 8.13 & $1.21 \%$ \\
\hline $\mathrm{f}_{2}$ & 32.59 & 32.13 & $1.03 \%$ \\
\hline $\mathrm{f}_{3}$ & 52.98 & 52.25 & $1.37 \%$ \\
\hline $\mathrm{f}_{4}$ & 57.76 & 56.88 & $0.81 \%$ \\
\hline $\mathrm{f}_{5}$ & 116.40 & 114.80 & $1.04 \%$ \\
\hline$P_{c r}(N)$ & 964.05 & 962.19 & $1.32 \%$ \\
\hline
\end{tabular}

\subsection{Effect of the thickness (h)}

For a single bay structure, the effect of the thickness (h) on dynamic behavior and critical buckling load is investigated for fixed boundary condition. Two different thickness parameters, $h_{1}=a / 100$ and $h_{2}=a / 50$, are selected, and the curvature is set as $R_{x x}=2 L_{b}$. 
Table 5: Free vibration and buckling analysis of the parabolic frame structure for $h_{l}=L_{b} / 100 h_{2}=L_{b} / 50$ (N.F.: Natural Frequency Values, $\mathrm{P}_{\text {cr }}$ : Critical Buckling Load, SW: SolidWorks Results, PS: Present Study Results, Err: Error)

\begin{tabular}{|c|c|c|c|c|c|c|}
\hline \multirow{2}{*}{$\begin{array}{c}N . F . \\
(H z)\end{array}$} & \multicolumn{3}{|c|}{$h_{1}=L_{b} / 100$} & \multicolumn{3}{c|}{$h_{2}=L_{b} / 50$} \\
\cline { 2 - 7 } & $\mathrm{SW}$ & $\mathrm{PS}$ & Err (\%) & SW & PS & Err (\%) \\
\hline $\mathrm{f}_{1}$ & 8.13 & 8.29 & $1.86 \%$ & 16.21 & 16.57 & $2.21 \%$ \\
\hline $\mathrm{f}_{2}$ & 31.09 & 32.05 & $3.08 \%$ & 62.15 & 64.06 & $3.07 \%$ \\
\hline $\mathrm{f}_{3}$ & 51.56 & 53.02 & $2.82 \%$ & 102.59 & 106.03 & $3.35 \%$ \\
\hline $\mathrm{f}_{4}$ & 60.54 & 59.61 & $1.53 \%$ & 120.73 & 119.07 & $1.37 \%$ \\
\hline $\mathrm{f}_{5}$ & 113.54 & 115.66 & $1.87 \%$ & 226.16 & 230.81 & $2.06 \%$ \\
\hline$P_{c r}(N)$ & 950.13 & 948.90 & $0.25 \%$ & 15337 & 15180 & $1.02 \%$ \\
\hline
\end{tabular}

As seen in Table 5, two different thickness (h) parameter is compared each other in terms of natural frequency and critical buckling load. The natural frequency values increases or decreases as the same as the thickness ratio as expected. The critical buckling load increases as the structure thickness increases. However, the increment is not the same as that of the natural frequency. This is because the ratio is not the same since the relation between the stiffness matrix and mass matrix is not the same as the stiffness matrix and geometric matrix.

\subsection{The Two-Bay structure}

In addition to the single-bay structure, the two-bay parabolic frame structure is also investigated. Free vibration analysis and buckling analysis are performed under all columns fixed boundary conditions. The curvature is taken as $\mathrm{R}_{\mathrm{xx}}=2 \mathrm{~L}_{\mathrm{b}}$ and the thickness is set as $\mathrm{h}=\mathrm{L}_{\mathrm{b}} / 100$.

The loading condition is given as is in Fig.8. The equivalent loading case for finite element analysis is given in Fig.9.

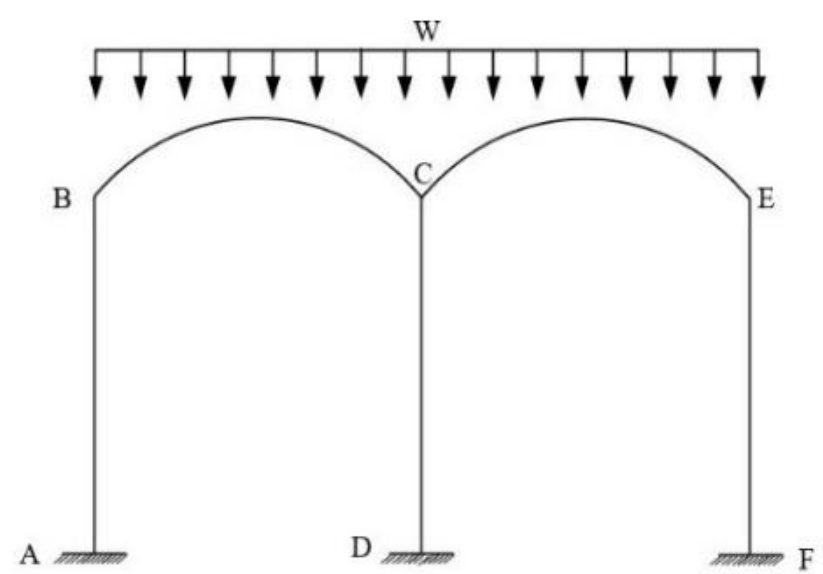

(a)

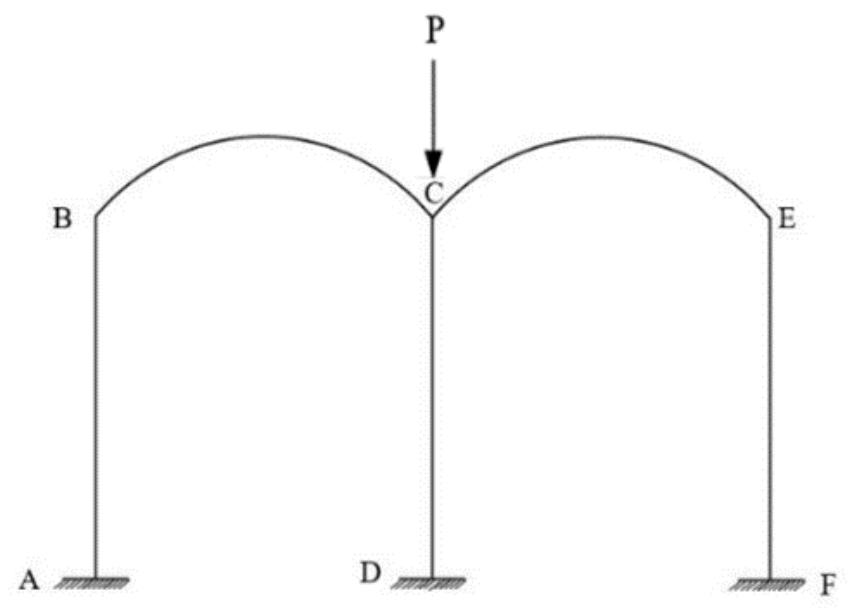

(b)

Figure 8: Distributed loading case for the two-bay parabolic frame structure 


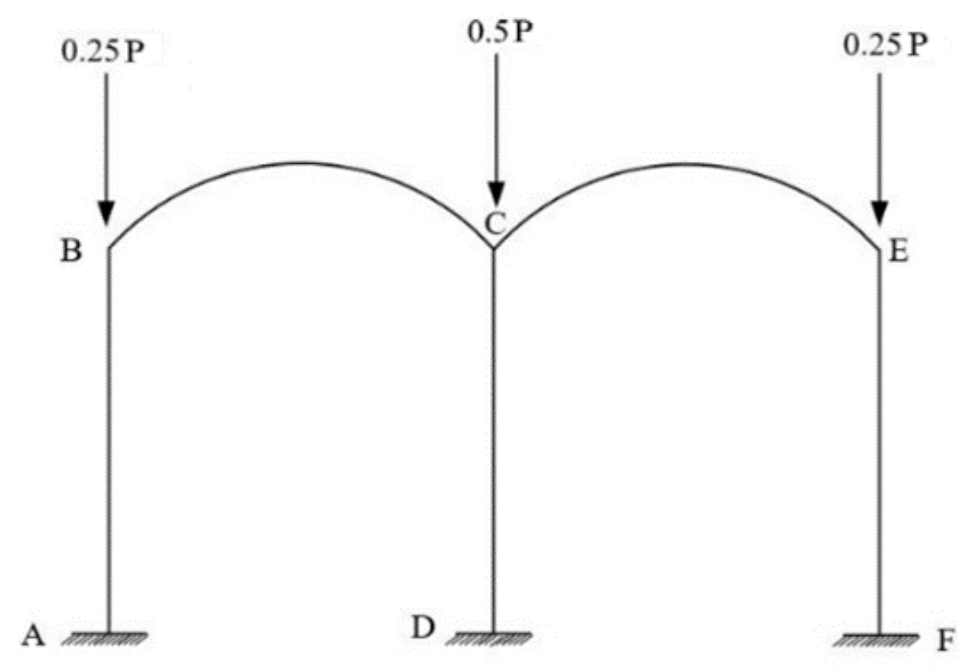

Figure 9: Equivalent loading case for the two-bay parabolic frame structure

Comparative results of the free vibration analysis and buckling analysis for the two-bay parabolic frame structure is given in Tables 6 and 7.

Table 6: Free vibration and buckling analysis of the two-bay parabolic frame structure for $\mathrm{R}_{\mathrm{xx}}=1.5 \mathrm{~L}_{\mathrm{b}}$ and $\mathrm{R}_{\mathrm{xx}}=2 \mathrm{~L}_{\mathrm{b}}$ (N.F.: Natural Frequency Values, $\mathrm{P}_{\mathrm{cr}}$ : Critical Buckling Load, SW: SolidWorks Results, PS: Present Study Results, Err: Error)

\begin{tabular}{|c|c|c|c|c|c|c|}
\hline \multirow{2}{*}{$\begin{array}{c}N . F . \\
(H z)\end{array}$} & \multicolumn{3}{|c|}{$R_{x x}=1.5 L_{b}$} & \multicolumn{3}{c|}{$R_{x x}=2 L_{b}$} \\
\cline { 2 - 7 } & $\mathrm{SW}$ & $\mathrm{PS}$ & $\operatorname{Err}(\%)$ & $\mathrm{SW}$ & $\mathrm{PS}$ & Err (\%) \\
\hline $\mathrm{f}_{1}$ & 7.42 & 7.66 & $3.29 \%$ & 7.47 & 7.67 & $2.71 \%$ \\
\hline $\mathrm{f}_{2}$ & 29.48 & 31.01 & $5.19 \%$ & 29.97 & 31.12 & $3.86 \%$ \\
\hline $\mathrm{f}_{3}$ & 34.45 & 37.73 & $9.52 \%$ & 35.74 & 38.26 & $7.04 \%$ \\
\hline $\mathrm{f}_{4}$ & 51.13 & 53.29 & $4.22 \%$ & 51.67 & 53.46 & $3.48 \%$ \\
\hline $\mathrm{f}_{5}$ & 59.98 & 59.77 & $0.34 \%$ & 59.37 & 59.30 & $0.12 \%$ \\
\hline$P_{c r}(N)$ & 1429.1 & 1453.7 & $1.72 \%$ & 1439.8 & 1455.3 & $1.08 \%$ \\
\hline
\end{tabular}

Table 7: Free vibration and buckling analysis of the two-bay parabolic frame structure for $R_{x x}=2.5 L_{b}$ and $R_{x x}=3 L_{b} \quad(N . F .:$ The Natural Frequency Values, $\mathrm{P}_{\mathrm{cr}}$ : The Critical Buckling Load, SW: SolidWorks Results, PS: Present Study Results, Err: Error)

\begin{tabular}{|c|c|c|c|c|c|c|}
\hline \multirow{2}{*}{$\begin{array}{c}\text { N.F. } \\
(H z)\end{array}$} & \multicolumn{3}{|c|}{$R_{x x}=2.5 L_{b}$} & \multicolumn{3}{c|}{$R_{x x}=3 L_{b}$} \\
\cline { 2 - 7 } & $\mathrm{SW}$ & $\mathrm{PS}$ & Err (\%) & SW & PS & Err (\%) \\
\hline $\mathrm{f}_{1}$ & 7.50 & 7.68 & $2.39 \%$ & 7.51 & 7.68 & $2.29 \%$ \\
\hline $\mathrm{f}_{2}$ & 30.23 & 31.19 & $3.20 \%$ & 30.38 & 31.24 & $2.83 \%$ \\
\hline $\mathrm{f}_{3}$ & 36.50 & 38.57 & $5.70 \%$ & 36.97 & 38.78 & $4.90 \%$ \\
\hline $\mathrm{f}_{4}$ & 51.93 & 53.57 & $3.15 \%$ & 52.10 & 53.63 & $2.94 \%$ \\
\hline $\mathrm{f}_{5}$ & 58.94 & 59.03 & $0.14 \%$ & 58.65 & 58.85 & $0.34 \%$ \\
\hline$P_{c r}(N)$ & 1437.2 & 1456.1 & $1.32 \%$ & 1448.3 & 1456.7 & $0.58 \%$ \\
\hline
\end{tabular}

As seen in Tables 6 and 7, agreement between the present finite element models and SolidWorks solution results is good. Differently from the single-bay results, the fifth natural frequency value decreases as the curvature increases. This is because the fifth mode is similar to the fourth mode of the single-bay structure which all components of the structure behave have the same displacement characteristics.

The critical buckling load changes in the same way as the curvature. 


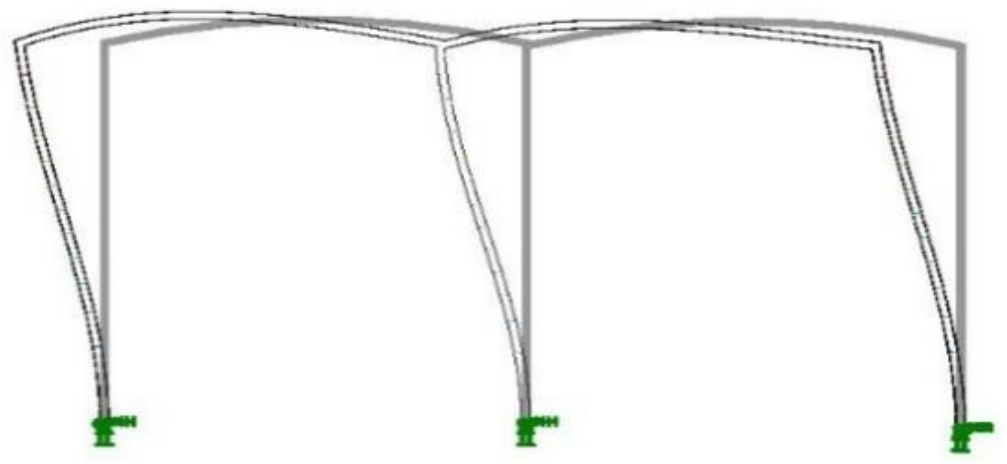

(a)

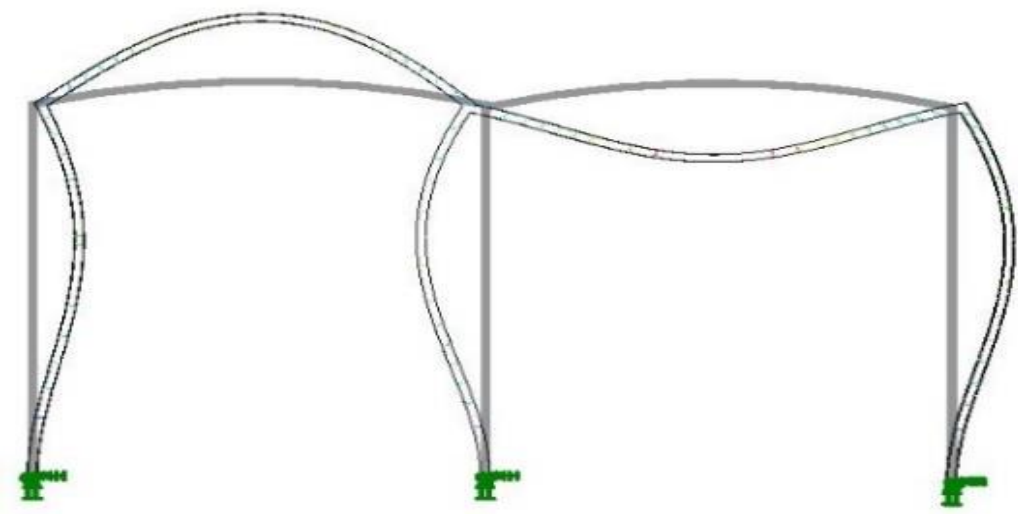

(b)

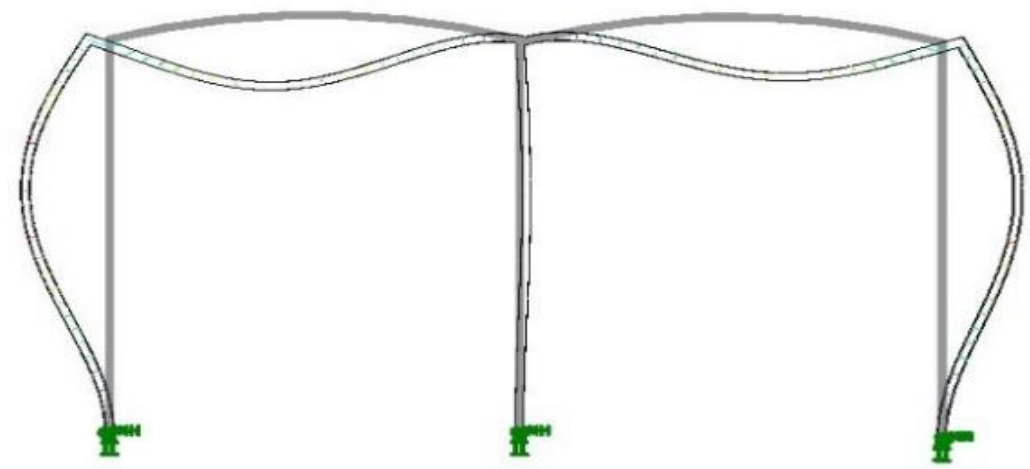

(c)

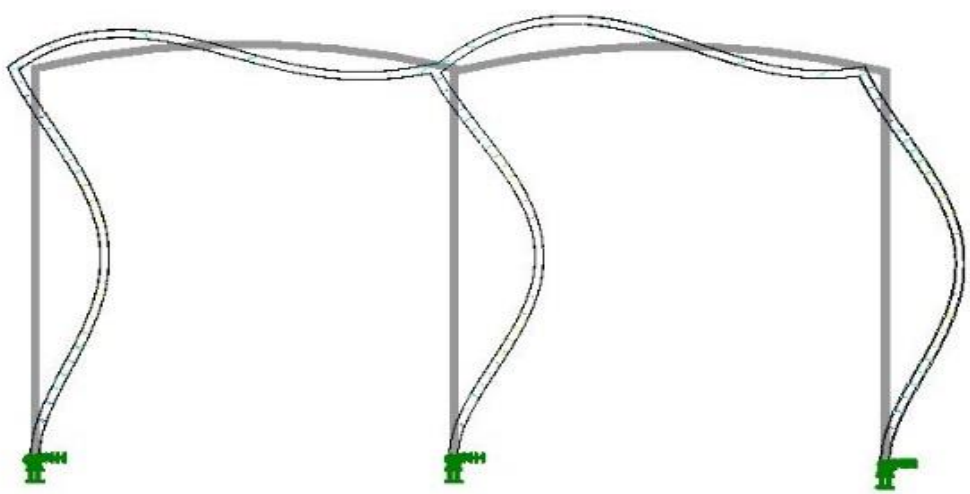

(d) 


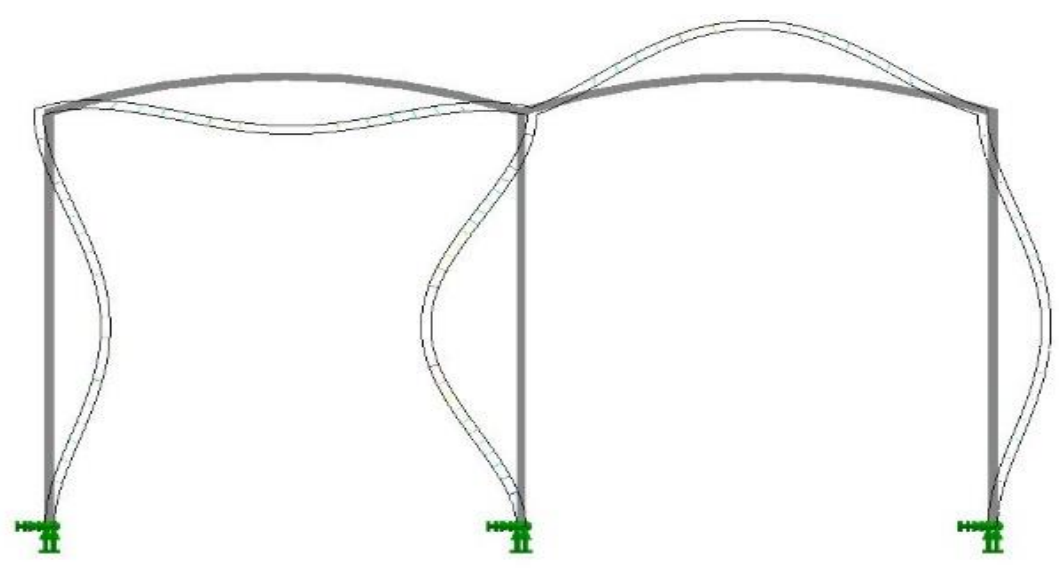

(e)

Figure 10: The first five modes of the two-bay parabolic frame structure

\section{Conclusions and Discussions}

In this paper, free vibration and buckling analysis of the parabolic frame structure are investigated by using the finite element method. According to the results given in section 3, it is concluded that

- The natural frequency values and critical buckling loads that are obtained via the finite element method by using a frame element are in very good agreement with SolidWorks results for both parabolic and straight frames.

- For the single-bay structure, all natural frequency values, except the fourth natural frequency value, increase as the radius of curvature increases. On the other hand, the fourth frequency value decreases. This is because the structural components behave in the same displacement characteristic in this mode.

- For the two-bay structure, all natural frequency values, except the fifth natural frequency value, increase as the radius of curvature increases. Similar to the single-bay structure, this is because the structural components behave in the same displacement characteristic in this mode.

- The critical buckling load increases when the radius of curvature increases for both single-bay and multi-bay parabolic frame structure.

- The equivalent loading approach that is used for straight frame structures in order to perform finite element analysis is also valid for parabolic frame structures under perpendicular distributed loading condition.

- As is expected, the natural frequency and the critical buckling values increase as the thickness of the parabolic frame structure increase.

\section{References}

[1] V. Leontovich, "Frames and Arches Condensed Solutions for Structural Analysis," McGraw Hill, New York, 1959.

[2] Chidamparam, P., \& Leissa, A. W. (1993). Vibrations of Planar Curved Beams, Rings, and Arches. Applied Mechanics Reviews, 46(9), 467-483. doi: 10.1115/1.3120374

[3] Kang, B., Riedel, C., \& Tan, C. (2003). Free vibration analysis of planar curved beams by wave propagation. Journal of Sound and Vibration, 260(1), 19-44. doi: 10.1016/s0022-460x(02)00898-2

[4] Zhu, Z. H., \& Meguid, S. A. (2004). Analysis of Three-Dimensional Locking-Free Curved Beam Element. International Journal of Computational Engineering Science, 05(03), 535-556. doi: $10.1142 / \mathrm{s} 1465876304002551$

[5] Akgöz, B., \& Civalek, Ö. (2013). Free vibration analysis of axially functionally graded tapered Bernoulli-Euler microbeams based on the modified couple stress theory. Composite Structures, 98, 314-322. doi: 10.1016/j.compstruct.2012.11.020

[6] Pradhan, K., \& Chakraverty, S. (2013). Free vibration of Euler and Timoshenko functionally graded beams by Rayleigh-Ritz method. Composites Part B: Engineering, 51, 175-184. doi: 10.1016/j.compositesb.2013.02.027 
[7] Eltaher, M., Emam, S. A., \& Mahmoud, F. (2012). Free vibration analysis of functionally graded sizedependent nanobeams. Applied Mathematics and Computation, 218(14), 7406-7420. doi: 10.1016/j.amc.2011.12.090

[8] Bazoune, A., \& Khulief, Y. (1992). A finite beam element for vibration analysis of rotating tapered timoshenko beams. Journal of Sound and Vibration, 156(1), 141-164. doi: 10.1016/0022460x(92)90817-h

[9] Cleghorn, W., Tabarrok, B., \& Lee, T. (1993). Vibration of Rings with Unsymmetrical Cross-Sections: A Finite Element Approach. Journal of Sound and Vibration, 168(1), 93-113. doi: 10.1006/jsvi.1993.1363

[10]Fotouhi, R. (2007). Dynamic analysis of very flexible beams. Journal of Sound and Vibration, 305(3), 521-533. doi: 10.1016/j.jsv.2007.01.032.

[11] Ozturk, H. (2011). In-plane free vibration of a pre-stressed curved beam obtained from a large deflected cantilever beam. Finite Elements in Analysis and Design, 47(3), 229-236. doi: 10.1016/j.finel.2010.10.003

[12]Kıral, B. G. (2009). Free Vibration Analysis of Delaminated Composite Beams. Science and Engineering of Composite Materials, 16(3). doi: 10.1515/secm.2009.16.3.209

[13] A Mehmood, A. (2014). Vibration Analysis Of Beam Subjected To Moving Loads Using Finite Element Method. IOSR Journal of Engineering, 4(5), 07-17. doi: 10.9790/3021-04510717

[14] Basci, M., Toridis, T., Khozeimeh, K., \& Fettahlioglu, O. (1979). Improved method of free vibration analysis of frame structures. Computers \& Structures, 10(1-2), 255-265. doi: 10.1016/00457949(79)90094-4

[15] Chan, S. L. (1990). Buckling Analysis of Structures Composed of Tapered Members. Journal of Structural Engineering, 116(7), 1893-1906. doi: 10.1061/(asce)0733-9445(1990)116:7(1893) 